\title{
The functions of plant cation/proton antiporters
}

\author{
W. DONG, D.-L. LI, N.-W. QIU, and Y.-G. SONG* \\ School of Life Science, Qufu Normal University, Qufu, 273165, Shandong, P.R. China
}

\begin{abstract}
The cation $/ \mathrm{H}^{+}$exchange is a basic process in transmembrane transport. The acquisition of genome sequences has now established that plants possess genes encoding a large number of cation/proton antiporter 1 (CPA1) proteins, few of which have been characterized with respect to their contribution to ion homeostasis. The CPA1s comprise plasma membrane, vacuolar, and endosomal forms, and they have been identified as important for a salinity tolerance. They are, however, also involved in both the control of cellular $\mathrm{pH}$ and $\mathrm{K}^{+}$homeostasis, and regulate processes over a wide range of physiological events, from vesicle trafficking to development.
\end{abstract}

Additional key words: $\mathrm{pH}$ and $\mathrm{K}^{+}$homeostasis, salinity tolerance, vesicle trafficking.

\section{Introduction}

The cation/proton antiporter1 (CPA1) class of transmembrane antiporters contribute to the transmembrane exchange of $\mathrm{Na}^{+}$or $\mathrm{K}^{+}$ion for $\mathrm{H}^{+}$, exploiting electrochemical gradients generated by various proton translocating enzymes such as $\mathrm{H}^{+}$-ATPase in the plasma membrane and vacuolar ATPase and pyrophosphatase (PPase) within intracellular compartments (Pardo et al. 2006, Rodríguez-Rosales et al. 2009). They are present in bacterial, plant, fungal, and animal cells. With the exception of yeast, all eukaryotic genomes sequenced to date contain multiple isoforms of them (Brett et al. 2005, Chanroj et al. 2012, Ford et al. 2012). Plant CPA1 genes have been assigned to either the $\mathrm{Na}^{+} / \mathrm{H}^{+}$antiporter (NhaP) or the $\mathrm{Na}^{(+)}-\mathrm{H}^{(+)}$exchanger (NHX)) clade (Brett et al. 2005, Chanroj et al. 2012). Genes allocated to the former clade encode proteins which localize to the plasma membrane and share similarity with the human sodium-hydrogen exchanger isoform-1 (NHE-1) proteins (Qiu et al. 2002, Chanroj et al. 2012), while those of the NHX clade localize to intracellular (IC) membranes. The
IC class I NHXs are deposited in the tonoplast and are plant-specific; IC class IIs are found in the endosome and are closely related to the yeast protein ScNHX1 and the human proteins NHE6 and NHE7 (Bowers et al. 2000, Brett et al. 2005, Chanroj et al. 2012). The Arabidopsis thaliana and rice $C P A 1$ gene families are almost identical in size: there are two isoforms of NhaP in A. thaliana (NHX7=SOS1 and NHX8) and one in rice salt overly sensitive1 (SOS1). The NHX clade is represented by six genes in A. thaliana and by five in rice: AtNHX1-4 and OsNHX1-4 encode intracellular-Is (IC-Is), while AtNHX5, AtNHX6, and OsNHX5 encode IC-IIs. The A. thaliana and rice IC-Is share $54-87 \%$ similarity at the polypeptide level, while the similarity between the three IC-IIs ranges from 72 to $79 \%$. The IC-I and IC-II sequences share only about $22 \%$ similarity.

Ion and $\mathrm{pH}$ homeostasis is critical for the operation of many cellular processes underlying plant development and growth. CPA1 activity is a major determinant of the cellular osmotic environment and hence of cell pressure

Submitted 18 September 2017, last revision 18 December 2017, accepted 5 January 2018.

Abbreviations: AKT1 - Arabidopsis $\mathrm{K}^{+}$transporter1; CPA1 - cation/proton antiporter 1; ER - endoplasmic reticulum; IC - intracellular; NhaP - $\mathrm{Na}^{+} / \mathrm{H}^{+}$antiporter; NHE - sodium-hydrogen exchanger isoform; $\mathrm{NHX}-\mathrm{Na}^{(+)}-\mathrm{H}^{(+)}$exchanger; PPase proton pumping pyrophosphatase; PVC - pre-vacuolar compartment; SOS1 - salt overly sensitive1; TGN - trans-Golgi network.

Acknowledgements: This work was supported by the Shandong Provincial Natural Science Foundation, China (ZR2015JL012, ZR2014CP013), the National Natural Science Foundation for the Youth of China (grant nos. 31300220, 31501328), the China Postdoctoral Science Foundation (2014M550366), and the Science and Technology Project of the Qufu Normal University (XKJ201320).

* Corresponding author; e-mail: SYG-0423@163.com 
potential. Coupled cation/proton exchange is central to the regulation of vacuolar and endosomal $\mathrm{pH}$ and ionic composition, thereby affecting protein processing and trafficking, as well as vesicular cargo composition and movement (Pardo et al. 2006, Rodriguez-Rosales et al. 2009). The conservation across species of the three classes of CPA1s (plasma membrane, endosomal, and vacuolar) implies an early appearance of these distinct functional classes during evolution (Bassil and Blumwald 2014). The suggestion is that they retain their compartment specificity. This review focuses on the physiological significance of the three classes of plant CPA1s.

\section{Salinity tolerance}

When exposed to a saline environment, plants inevitably accumulate $\mathrm{Na}^{+}$ions (although to a varying extent), driven by the major gradient in $\mathrm{Na}^{+}$concentration between the soil solution and the interior of the plant. A significant component of plant salinity tolerance is the capacity to limit the uptake of $\mathrm{Na}^{+}$into the root. Interspecific comparisons of $\mathrm{Na}^{+}$flux and the rate of $\mathrm{Na}^{+}$ accumulation suggest that $70-95 \%$ of the $\mathrm{Na}^{+}$entering the root symplast is actively returned to the rhizosphere via an energetically costly processes (Tester and Davenport 2003). To date, only the charge neutral exchange achieved by the plasma membrane $\mathrm{Na}^{+}$/proton exchanger SOS1 has been subjected to rigorous quantification (Apse and Blumwald 2007, Jiang et al. 2010, Zhang et al. 2017). The over-expression of its encoding gene (or certain homologs) enhances salinity tolerance in both A. thaliana and tobacco (Shi et al. 2003, Yang et al. 2009, Yue et al. 2012). Plasma membrane vesicles formed by the $A$. thaliana loss-of-function $\operatorname{sos} 1$ mutant have some $\mathrm{Na}^{+}$/proton exchange activity (Qiu et al. 2002, Shi et al. 2002). The closely related protein AtNHX8 is thought to be a plasma membrane localized $\mathrm{Li}^{+} /$proton antiporter which responds specifically to the stress imposed by an excess of $\mathrm{Li}^{+}$ions, since T-DNA insertion mutants of its encoding gene are more sensitive to $\mathrm{Li}^{+}$than the wild type is; the effect does not extend to the other monovalent cations $\mathrm{Na}^{+}, \mathrm{K}^{+}$, or $\mathrm{Cs}^{+}$(An et al. 2007). The implication is that additional plasma membrane exchangers are likely present; nevertheless, the genetic evidence confirms that SOS1 makes a major contribution to salinity tolerance.

The export of $\mathrm{Na}^{+}$only exacerbates the osmotic and ionic imbalance, thereby aggravating the primary stress. Returning $\mathrm{Na}^{+}$to the medium can therefore be only an interim solution and cannot on its own confer a prolonged tolerance to soil salinity. Since the efficiency of $\mathrm{Na}^{+}$ removal is not $100 \%$, over time $\mathrm{Na}^{+}$ions will inevitably accumulate, initially in the root and later throughout the plant. As a second line of defense, plants use the IC-I enzyme NHX to sequester $\mathrm{Na}^{+}$ions within their cellular vacuoles, thereby both protecting the cytosol from $\mathrm{Na}^{+}$ toxicity and encouraging the osmotically driven uptake of water (Apse and Blumwald 2007). The over-expression of either AtNHX1 or genes encoding isoforms of NHX increase salinity tolerance in a variety of plant species (Apse et al. 1999, Hamada et al. 2001, Ohta et al. 2002, Brini et al. 2007, Zhang et al. 2012). The simultaneous over-expression of AtNHX1 and AtSOS1 significantly mitigates loss of biomass induced by salinity stress (Pehlivan et al. 2016). In contrast, both tomato plants deficient for NHX2 (IC-II NHX) and the $A$. thaliana $n h x 5 n h x 6$ double mutant are hypersensitive to salinity (Rodríguez-Rosales et al. 2008, Bassil et al. 2011a). Plants lacking vacuolar V-ATPase show a reduced capacity to store nitrate and do not over-accumulate $\mathrm{Zn}^{2+}$, and they are not over-sensitive to salinity. On the other hand, plants with increased activity of endosomal or trans-Golgi network (TGN) localized V-ATPase are sensitive to salinity (Krebs et al. 2010). The implication is that the endosomal/vesicle system provides an important means of protecting plants against the damage generated by salinity stress as supported by other studies (Mazel et al. 2004, Hamaji et al. 2009, Hernandez et al. 2009). The salinity tolerance of $N H X$ over-expressing plants seems to be independent of both the species origin of the transgene and the identity of the encoded isoform: both IC-I and IC-II antiporters appear to have a similar role in salinity tolerance.

As NHX transporters also transport $\mathrm{K}^{+}$ions, they are expected to exert an effect on intercellular $\mathrm{K}^{+}$content, especially in the case of $\mathrm{K}^{+}$specific IC-II antiporters. The over-expression of either AtNHX1 or AtNHX2 has been shown to increase the content of both $\mathrm{K}^{+}$and $\mathrm{Na}^{+}$in ENA (the main $\mathrm{Na}^{+}$efflux system) and $S c N H X 1$-disrupted yeast cells grown in the presence of $\mathrm{NaCl}$ (Quintero et al. 2000, Yokoi et al. 2002). The constitutive expressions of AtNHX5 and LeNHX2 encoding the IC-II antiporter raise the cellular content of $\mathrm{K}^{+}$, but reduce the content of $\mathrm{Na}^{+}$ (Yokoi et al. 2002, Venema et al. 2003). SOS1 appears to lack the capacity to transport $\mathrm{K}^{+}$both in its basal state and after its activation by SOS2/SOS3 kinase. Plants experiencing a high concentration of $\mathrm{Na}^{+}$in the soil solution are not able to take up $\mathrm{K}^{+}$due to competition for the transporter binding sites involved in $\mathrm{K}^{+}$uptake (Hasegawa et al. 2000). Therefore, the removal of $\mathrm{Na}^{+}$ from the cytoplasm achieved by SOS1 protects cells against loss of the membrane capacity to transport $\mathrm{K}^{+}$. This is particularly in the case of the AKT1 (Arabidopsis $\mathrm{K}^{+}$transporter1) $\mathrm{K}^{+}$channel (Qi et al. 2004). The inference is that plant CPA1-mediated salinity tolerance is more than just a consequence of the accumulation of $\mathrm{Na}^{+}$inside the vacuole and its expulsion from the cell; rather, at least a part of this tolerance reflects the effect of CPA1 on the cytoplasmic content of $\mathrm{K}^{+}$. 


\section{Homeostasis of $\mathbf{K}^{+}$}

Some CPA1s, and especially the NHXs, have been suggested to participate in $\mathrm{K}^{+}$homeostasis under normal growth conditions (Adem et al. 2014). In addition to being an essential nutrient, the $\mathrm{K}^{+}$acts to balance intracellular charge and also represents a co-factor for certain cytosolic enzymes. The majority of cellular $\mathrm{K}^{+}$is found in the vacuole, where it maintains pressure potential and so indirectly drives cell expansion (Bassil et al. 2012). The acidification of the cytoplasm may serve as a signal to induce either high affinity $\mathrm{K}^{+}$uptake from the soil or $\mathrm{K}^{+}$efflux from the vacuole (Walker et al. 1996). A reduction in the $\mathrm{pH}$ gradient across the tonoplast membrane may attenuate the accumulation of vacuolar $\mathrm{K}^{+}$driven by IC-I NHX. In grape, NHX1 expression was significantly upregulated at veraison and during cell expansion where berry vacuolar $\mathrm{K}^{+}$accumulation and a drop in acidity occur (Hanana et al. 2007). Antiport activity is reduced in A. thaliana $n h x 1$ null mutants, which form smaller cells and display a reduced expansion of highly vacuolated cells; these effects may be related to the vacuolar $\mathrm{K}^{+}$deficit needed to ensure pressure potential for cell expansion (Apse et al. 2003). A microarray-based transcriptomic analysis has indicated that genes encoding high affinity $\mathrm{K}^{+}$uptake transporters are up-regulated in the absence of a functional copy of NHX1, which supports the notion that AtNHX1 is involved in $\mathrm{K}^{+}$homeostasis (Sottosanto et al. 2004). While no clear phenotype is induced when the closely

\section{Homeostasis of pH}

Cellular $\mathrm{pH}$ homeostasis is highly critical for cellular function. Cytoplasmic $\mathrm{pH}$ is controlled primary by proton pumps and metabolic processes producing protons or hydroxyl ions. Luminal $\mathrm{pH}$ is not uniform throughout the cell; it is dependent on the intracellular compartment (Paroutis et al. 2004). In vivo measurement has revealed that the $\mathrm{pH}$ ranges from $\mathrm{pH} 7.1$ in the endoplasmic reticulum (ER) to about 5.5 in the vacuole; the TGN is more acidic than the pre-vacuolar compartments which are intermediate organelles where secretory and endocytic traffic leads to vacuole (Yu et al. 2006, Martinière et al. 2013). Given the involvement of CPA1s in proton leakage, it is hardly surprising that they are able to regulate $\mathrm{pH}$ in the cytoplasm or in vesicles depending on their sub-cellular localization. Evidence for intracellular NHX-dependent $\mathrm{pH}$ regulation first arose from a study of the pigmentation of the petals of Ipomea sp. (Yoshida et al. 2005). During development, petals begin to accumulate anthocyanins in their vacuoles: this results in red colour at low vacuolar $\mathrm{pH}$ and blue colour as the $\mathrm{pH}$ increases. The increase of petal vacuolar $\mathrm{pH}$ from 6.5 to 7.5 is accompanied by an enhanced activity of related isoform NHX2 is knocked out, the double $n h x \operatorname{lnh} x 2$ mutant suffers a substantial reduction in cell expansion and growth, especially in the rapidly elongating filament (Bassil et al. 2011b). The vacuolar $\mathrm{K}^{+}$content in the double mutant is only one third of that in wild type plants, both in the root and in the leaf (Bassil et al. 2011b, Barragán et al. 2012). Stomatal opening depends on an increase in the guard cell vacuolar $\mathrm{K}^{+}$ content, a process which relies on vacuolar NHXs (Andrés et al. 2014). These observations highlight the importance of vacuolar NHX for cellular $\mathrm{K}^{+}$homeostasis.

The knockout/knockdown of NHX results in severe growth defects. For example, in tomato, the knockdown of LeNHX2 induces growth retardation (RodríguezRosales et al. 2008), and similarly in A. thaliana, the simultaneous loss of $N H X 5$ and $N H X 6$ reduces cell size, and slows both floral development and root growth (Bassil et al. 2011a). $\mathrm{K}^{+}$content in the $n h x 5 n h x 6$ double mutant is greatly reduced compared to that present in wild type tissue (Wang et al. 2015). The constitutive expression of either NHX5 or NHX6 in the double mutant rescues root growth. Thus endosomal NHXs make a significant contribution to growth and development, possibly via their support of $\mathrm{K}^{+}$homeostasis. However, the lack of targeted $\mathrm{K}^{+}$specific microprobes inhibits measurement of the $\mathrm{K}^{+}$content in the vesicles, preventing the identification of the role of endosomal/vesicular NHXs in $\mathrm{K}^{+}$homeostasis.

V-ATPase, proton-PPase, and NHX1. Direct measurements of vacuolar $\mathrm{pH}$ in $n h x$ mutants strongly suggest that vacuolar NHX antiporters are important for the regulation of vacuolar $\mathrm{pH}$. In the roots of the $A$. thaliana $n h x \operatorname{lnh} x 2$ double mutant, the vacuolar environment is markedly more acidic than in the wild type in the cells of elongation and maturation zones, especially in the cortical cells (Bassil et al. 2011b). Cells in the root tips tend to have more acidic $\mathrm{pH}$ than mature root zone cells. However, there is little difference between the cellular $\mathrm{pH}$ of $n h x \operatorname{lnh} x 2$ and wild type plants in root tip cells (Barragán et al. 2012). The implication is that NHX antiporter activity is more pronounced in cells which need to raise their vacuolar volume to drive their elongation. Reguera et al. (2015) have used luorin-based $\mathrm{pH}$ sensors to measure the luminal $\mathrm{pH}$ within the Golgi bodies, the TGN, and the late pre-vacuolar compartment (LPVC); their finding is that $\mathrm{pH}$ in these compartments in the nhx5nhx6 double mutant is lower than in the wild type, which is taken to imply that endosomal/vesicular NHXs increase vesicle pH. This observation was supported by Wang et al. (2015) who showed that 
nhx5nhx6 has a reduced vacuolar $\mathrm{pH}$ as measured with the semimicro-electrode. Although the involvement of plant NHX transporters in cytoplasmic $\mathrm{pH}$ regulation has yet to be demonstrated, the use of fluorescent probes has shown that the loss of a functional copy of AtSOS1 results

\section{Potential functions of plant $C P A 1$ s}

The recently uncovered functionality of the endosomelocalized AtNHX5 and AtNHX6 proteins is particularly intriguing. Not unlike the situation in yeast (Bowers et al. 2000) and animal cells (Casey et al. 2010, Ohgaki et al. 2011), differential gene expression in the $n h x 5 n h x 6$ double mutant is largely associated with vesicular trafficking and with defects in trafficking to the vacuole (Bassil et al. 2011a). Using the endocytotic tracer, the lipophilic styryl dye (FM4-64), and monitoring the progressive fluorescence labelling of endomembranes, it was shown that labelling of the vacuole was severely delayed in nhx $5 \mathrm{nhx} 6$. In addition, trafficking of newly synthesized carboxypeptidase Y-green fluorescent protein (CPY-GFP), which normally accumulates in the vacuole, was transported to the apoplast in $n h x 5 n h x 6$ plants. (Bassil et al. 2012). A functional link between the VATPase complex and NHX5 and NHX6 has been proposed, based on the extensive co-localization of the TGN-localized V-ATPase with NHX5 and NHX6 (Bassil et al. 2011a). The proposal is that endosomal NHXs control vesicular trafficking, probably via their regulation of endosomal ionic and $\mathrm{pH}$ homeostases. However, $\mathrm{pH}$ is not the only maintainer of endosomal enzyme activity and protein stability, as it is also involved in the determination of vesicle identity, the regulation of receptor and cargo interactions, and ultimately endomembrane trafficking (Paroutis et al. 2004). In vivo measurements of the vesicular luminal $\mathrm{pH}$ status of endomembrane compartments and their contribution to the regulation of protein maturation should aid in establishing the biochemical basis of these processes.

Seed storage proteins are synthesized as precursors in the ER and then they are transported into the protein storage vacuoles (PSVs), and converted to mature forms.

\section{Conclusions}

Genetic analysis provides compelling evidence supporting the idea that the three classes of CPA1 (plasma membrane, vacuolar, and endosomal) regulate a range of cellular and physiological processes, including cell expansion, cation homeostasis, osmotic and pressure potential, $\mathrm{pH}$ homeostasis, vesicle trafficking, stomatal function, as well as floral development. The availability of multiple CPA1 knockout lines together with the development of platforms able to measure in vivo $\mathrm{pH}$ and ion content in various intracellular compartments has in an altered $\mathrm{pH}$ homeostasis within both the root cell cytosol and vacuole, probably due to an alteration in the proton flux through the plasma membrane (Shabala et al. 2005, Oh et al. 2010).

Studies have shown that proteins are transported to the vacuole through a vesicle-mediated trafficking pathway that includes the ER, Golgi, TGN, and multivesicular bodies (MVB) in PVC. Hence, the Golgi, TGN, and $\mathrm{MVB} / \mathrm{PVC}$ are major protein sorting stations in vesicular transport (Qiu et al. 2016). AtNHX5 and AtNHX6 are localized to the Golgi, TGN, and PVC, where they overlap with the protein trafficking pathway. The IC-I antiporters may also participate in intracellular vesicle trafficking, since the transcription of a large number of genes encoding proteins associated with intravesicular trafficking, trafficking to the nucleus, and processing in the Golgi bodies are altered in an $n h x 1$ T-DNA insertional mutant (Sottosanto et al. 2004).

So far, the major focus of CPA1 expression has been in the context of salinity stress, for example, the saltinduced AtCAPE1 negatively regulated salt tolerance by suppressing several salt-tolerance genes functioning in the production of osmolytes, detoxification, stomatal closure control, and cell membrane protection. AtNHX1 and $A t N H X 2$ play an important role in cell expansion and flower development by regulating intravacuolar $\mathrm{K}^{(+)}$ content and pH (Fukuda et al. 1999, Quintero et al. 2000, Brini et al. 2005, Zahran et al. 2007, Chien et al.2015, Bassil et al. 2011b). However, some members of this gene family appear to be inducible by abscisic acid (Venema et al. 2003, Yokoi et al. 2002), KCl (Fukuda et al. 1999, 2004a, 2004b), dehydration (Li et al. 2006) and/or hyper-osmotic stresses (Fukuda et al. 1999, 2004a, 2004b, Yokoi et al. 2002). The isolation of certain $N H X$ genes from Morus atropurpurea has recently shown that they are not only inducible by salinity, drought, and abscisic acid, but also by salicylic acid, hydrogen peroxide, and methyl jasmonate (Cao et al. 2016).

enabled deeper understanding the functions of these proteins. The identification of the protein partners regulating activities of these transporters are required to elucidate the underlying mechanisms. In response to salinity stress, the three classes of CPA1 seem to operate in tandem. In addition, they are important for the maintenance of cellular $\mathrm{pH}$ and $\mathrm{K}^{+}$content. They act cooperatively to regulate a range of processes from vesicle trafficking and cell expansion to plant development. 


\section{References}

Adem, G.D., Roy, S.J., Zhou, M., Bowman, J.P., Shabala, S.: Evaluating contribution of ionic, osmotic and oxidative stress components towards salinity tolerance in barley. BMC Plant Biol. 14: 113-125, 2014.

An, R., Chen, Q.J., Chai, M.F., Lu, P.L., Su, Z., Qin, Z.X., Chen, J., Wang, X.C.: AtNHX8, a member of the monovalent cation: proton antiporter-1 family in Arabidopsis thaliana, encodes a putative $\mathrm{Li} / \mathrm{H}$ antiporter. Plant J. 49: 718-728, 2007.

Andrés, Z., Pérez-Hormaeche, J., Leidi, E.O., Schlücking, K., Steinhorst, L., McLachlan, D.H., Schumacher, K., Hetherington, A.M., Kudla, J., Cubero, B., Pardo, J.M.: Control of vacuolar dynamics and regulation of stomatal aperture by tonoplast potassium uptake. - Proc. nat. Acad. Sci. USA 111: E1806-1814, 2014.

Apse, M.P., Aharon, G.S., Snedden, W.A., Blumwald, E.: Salt tolerance conferred by over expression of a vacuolar $\mathrm{Na}^{+} / \mathrm{H}^{+}$ antiport in Arabidopsis. - Science 285: 1256-1258, 1999.

Apse, M.P., Blumwald, E.: $\mathrm{Na}^{+}$transport in plants. - FEBS Lett. 581: 2247-2254, 2007.

Apse, M.P., Sottosanto, J.B., Blumwald, E.: Vacuolar cation $/ \mathrm{H}^{+}$ exchange, ion homeostasis, and leaf development are altered in a T-DNA insertional mutant of AtNHX1, the Arabidopsis vacuolar $\mathrm{Na}^{+} / \mathrm{H}^{+}$antiporter. - Plant J. 36: 229-239, 2003.

Barragán, V., Leidi, E.O., Andrés, Z., Rubio, L., De, Luca. A., Fernández, J.A., Cubero, B., Pardo, J.M.: Ion exchangers NHX1 and NHX2 mediate active potassium uptake into vacuoles to regulate cell turgor and stomatal function in Arabidopsis. - Plant Cell 24: 1127-1142, 2012.

Bassil, E., Blumwald, E.: The ins and outs of intracellular ion homeostasis: NHX-type cation/ $\mathrm{H}^{(+)}$transporters. - Curr. Opin. Plant Biol. 22: 1-6, 2014.

Bassil, E., Coku, A., Blumwald, E.: Cellular ion homeostasis: emerging roles of intracellular $\mathrm{NHX} \mathrm{Na} / \mathrm{H}^{+}$antiporters in plant growth and development. - J. exp. Bot. 63: 5727-5740, 2012.

Bassil, E., Ohto, M.A., Esumi, T., Tajima, H., Zhu, Z., Cagnac, O.: The Arabidopsis intracellular $\mathrm{Na}^{+} / \mathrm{H}^{+}$antiporters NHX5 and NHX6 are endosome associated and necessary for plant growth and development. - Plant Cell 23: 224-239, 2011 a.

Bassil, E., Tajima, H., Liang, Y.C., Ohto, M.A., Ushijima, K., Nakano, R., Esumi, T., Coku, A., Belmonte, M., Blumwald, E.: The Arabidopsis $\mathrm{Na}^{+} / \mathrm{H}^{+}$antiporters NHX1 and NHX2 control vacuolar $\mathrm{pH}$ and $\mathrm{K}^{+}$homeostasis to regulate growth, flower development, and reproduction. - Plant Cell 23: 3482-3497, $2011 \mathrm{~b}$.

Bowers, K., Levi, B.P., Patel, F.I., Stevens, T.H.: The sodium/proton exchanger Nhx1p is required for endosomal protein trafficking in the yeast Saccharomyces cerevisiae. Mol. Biol. Cell 11: 4277-4294, 2000.

Brett, C.L., Donowitz, M., Rao, R.: Evolutionary origins of eukaryotic sodium/proton exchangers. - Amer. J. Physiol. cell. Physiol. 288: C223-239, 2005.

Brini, F., Gaxiola, R.A., Berkowitz, G.A., Masmoudi, K.: Cloning and characterization of a wheat vacuolar cation/ proton antiporter and pyrophosphatase proton pump. - Plant Physiol. Biochem. 43: 347-354, 2005.

Brini, F., Hanin, M., Mezghani, I., Berkowitz, G.A., Masmoudi, K.: Overexpression of wheat $\mathrm{Na}^{+} / \mathrm{H}^{+}$antiporter TNHX1 and $\mathrm{H}^{+}$-pyrophosphatase TVP1 improve salt- and drought-stress tolerance in Arabidopsis thaliana plants. - J. exp. Bot. 58:
301-308, 2007.

Cao, B., Long, D., Zhang, M., Liu, C., Xiang, Z., Zhao, A.: Molecular characterization and expression analysis of the mulberry $\mathrm{Na}^{(+)} / \mathrm{H}^{(+)}$exchanger gene family. - Plant Physiol. Biochem. 99: 49-55, 2016.

Casey, J.R., Grinstein, S., Orlowski, J.: Sensors and regulators of intracellular pH. - Nat. Rev. mol. cell. Biol. 11: 50-61, 2010.

Chanroj, S., Wang, G., Venema, K., Zhang, M.W., Delwiche, C.F., Sze, H.: Conserved and diversified gene families of monovalent cation $/ \mathrm{H}^{+}$antiporters from algae to flowering plants. - Front. Plant Sci. 3: 25-42, 2012.

Chien, P.S., Nam, H.G., Chen, Y.R.: A salt-regulated peptide derived from the CAP superfamily protein negatively regulates salt-stress tolerance in Arabidopsis. - J. exp. Bot. 66: 5301-5313, 2015.

Ford, B.A., Ernest, J.R., Gendall, A.R.: Identification and characterization of orthologs of AtNHX5 and AtNHX6 in Brassica napus. - Front. Plant Sci. 3: 208-219, 2012.

Fukuda, A., Nakamura, A., Tanaka, Y.: Molecular cloning and expression of the $\mathrm{Na}^{+} / \mathrm{H}^{+}$exchanger gene in Oryza sativa. Biochim. biophys. Acta 1446: 149-155, 1999.

Fukuda, A., Chiba, K., Maeda, M., Nakamura, A., Maeshima, M., Tanaka, Y.: Effect of salt and osmotic stresses on the expression of genes for the vacuolar $\mathrm{H}^{+}$pyrophosphatase, $\mathrm{H}^{+}$ATPase subunit A, and $\mathrm{Na}^{+} / \mathrm{H}^{+}$antiporter from barley. J. exp. Bot. 55: 585-594, 2004a.

Fukuda, A., Nakamura, A., Tagiri, A., Tanaka, H., Miyao, A., Hirochika, H., Tanaka, Y.: Function, intracellular localization and the importance in salt tolerance of a vacuolar $\mathrm{Na}^{+} / \mathrm{H}^{+}$antiporter from rice. - Plant Cell Physiol. 45: 146-159, 2004b.

Hamada, A., Shono, M., Xia, T., Ohta, M., Hayashi, Y., Tanaka, A., Hayakawa T.: Isolation and characterization of a $\mathrm{Na}^{+} / \mathrm{H}^{+}$antiporter gene from the halophyte Atriplex gmelini. - Plant mol. Biol. 46: 35-42, 2001.

Hamaji, K., Nagira, M., Yoshida, K., Ohnishi, M., Oda, Y., Uemura, T., Goh, T., Sato, M.H., Morita, M.T., Tasaka, M., Hasezawa, S., Nakano, A., Hara-Nishimura, I., Maeshima, M., Fukaki, H., Mimura, T.: Dynamic aspects of ion accumulation by vesicle traffic under salt stress in Arabidopsis. - Plant Cell Physiol. 50: 2023-2033, 2009.

Hanana, M., Cagnac, O., Yamaguchi, T., Hamdi, S., Ghorbel, A., Blumwald, E.: A grape berry (Vitis vinifera L.) cation/proton antiporter is associated with berry ripening. Plant Cell Physiol. 48: 804-811, 2007.

Hasegawa, P.M., Bressan, R.A., Zhu, J.K., Bohnert, H.J.: Plant cellular and molecular responses to high salinity. - Annu. Rev. Plant Physiol. Plant mol. Biol. 51: 463-499, 2000.

Hernandez, A., Jiang, X.Y., Cubero, B., Nieto, P.M., Bressan, R.A., Hasegawa, P.M., Pardo, J.M.: Mutants of the Arabidopsis thaliana cation $/ \mathrm{H}^{+}$antiporter AtNHX1 conferring increased salt tolerance in yeast. The endosome/ prevacuolar compartment is a target for salt toxicity. - J. biol. Chem. 284: 14276-14285, 2009.

Jiang, X., Leidi, E.O., Pardo, J.M.: How do vacuolar NHX exchangers function in plant salt tolerance? - Plant Signal Behav. 5: 792-795, 2010.

Krebs, M., Beyhl, D., Gorlich, E., Al-Rasheid, K.A., Marten, I., Stierhof, Y.D., Hedrich, R., Schumacher, K.: Arabidopsis $\mathrm{V}$-ATPase activity at the tonoplast is required for efficient 
nutrient storage but not for sodium accumulation. -Proc. nat. Acad. Sci. USA 107: 3251-3256, 2010.

Li, W.Y., Wong, F.L., Tsai, S.N., Phang, T.H., Shao, G., Lam, H.M.: Tonoplast-located GmCLC1 and GmNHX1 from soybean enhance $\mathrm{NaCl}$ tolerance in transgenic bright yellow (BY)-2 cells. - Plant Cell Environ. 29: 1122-1137, 2006.

Martinière, A., Bassil, E., Jublanc, E., Alcon, C., Reguera, M., Sentenac, H., Blumwald, E., Paris, N.: In vivo intracellular $\mathrm{pH}$ measurements in tobacco and Arabidopsis reveal an unexpected $\mathrm{pH}$ gradient in the endomembrane system. Plant Cell 25: 4028-4043, 2013.

Mazel, A., Leshem, Y., Tiwari, B.S., Levine, A.: Induction of salt and osmotic stress tolerance by over expression of an intracellular vesicle trafficking protein AtRab7 (AtRabG3e). - Plant Physiol. 134: 118-128, 2004.

Oh, D.H., Lee, S.Y., Bressan, R.A., Yun, D.J., Bohnert, H.J.: Intracellular consequences of SOS1 deficiency during salt stress. - J. exp. Bot. 61: 1205-1213, 2010.

Ohgaki, R., Van, I., Jzendoorn, S.C., Matsushita, M., Hoekstra, D., Kanazawa, H.: Organellar $\mathrm{Na}^{+} / \mathrm{H}^{+}$exchangers: novel players in organelle $\mathrm{pH}$ regulation and their emerging functions. - Biochemistry 50: 443-445, 2011.

Ohta, M., Hayashi, Y., Nakashima, A., Hamada, A., Tanaka, A., Nakamura, T., Hayakawa, T.: Introduction of a $\mathrm{Na}^{+} / \mathrm{H}^{+}$ antiporter gene from Atriplex gmelini confers salt tolerance to rice. - FEBS Lett. 532: 279-282, 2002.

Pardo, J.M., Cubero, B., Leidi, E.O., Quintero, F.J.: Alkali cation exchangers: roles in cellular homeostasis and stress tolerance. - J. exp. Bot. 57: 1181-1199, 2006.

Paroutis, P., Touret, N., Grinstein, S.: The pH of the secretory pathway: measurement, determinants, and regulation. Physiology 19: 207-215, 2004.

Pehlivan, N., Sun, L., Jarrett, P., Yang, X., Mishra, N., Chen, L., Kadioglu, A., Shen, G., Zhang, H.: Co-overexpressing a plasma membrane and a vacuolar membrane sodium/proton antiporter significantly improves salt tolerance in transgenic Arabidopsis plants. - Plant Cell Physiol. 57: 1069-1084, 2016.

Qi, Z., Spalding, E.P.: Protection of plasma membrane $\mathrm{K}^{+}$ transport by the salt overly sensitive $1 \mathrm{Na}^{+}-\mathrm{H}^{+}$antiporter during salinity stress. - Plant Physiol. 136: 2548-2555, 2004.

Qiu, Q.S.: Plant endosomal NHX antiporters: activity and function. - Plant Signal Behav. 11: e1147643, 2016.

Qiu, Q.S., Guo, Y., Dietrich, M.A., Schumaker, K.S., Zhu, J.K.: Regulation of SOS1, a plasma membrane $\mathrm{Na}^{+} / \mathrm{H}^{+}$exchanger in Arabidopsis thaliana, by SOS2 and SOS3. - Proc. nat. Acad. Sci. USA 99: 8436-8441, 2002.

Quintero, F.J., Blatt, M.R., Pardo, J.M.: Functional conservation between yeast and plant endosomal $\mathrm{Na}^{(+)} / \mathrm{H}^{(+)}$antiporters. FEBS Lett. 471: 224-228, 2000.

Quintero, F.J., Ohta, M., Shi, H., Zhu, J.K., Pardo, J.M.: Reconstitution in yeast of the Arabidopsis SOS signaling pathway for $\mathrm{Na}^{+}$homeostasis. - Proc. nat. Acad. Sci. USA 99: 9061-9066, 2002.

Reguera, M., Bassil, E., Tajima, H., Wimmer, M., Chanoca, A., Otegui, MS., Paris, N., Blumwald, E.: pH regulation by NHX-type antiporters is required for receptor-mediated protein trafficking to the vacuole in Arabidopsis. - Plant Cell 27: 1200-1217, 2015.

Rodríguez-Rosales, M.P., Jiang, X.J., Gálvez, F.J., Aranda, M.N., Cubero, B., Venema, K.: Overexpression of the tomato $\mathrm{K}^{+} / \mathrm{H}^{+}$antiporter LeNHX2 confers salt tolerance by improving potassium compartmentalization. - New Phytol. 179: 366-377, 2008.

Rodríguez-Rosales, M.P., Gálvez, F.J., Huertas, R., Aranda, M.N., Baghour, M., Cagnac, O., Venema, K.: Plant NHX cation/proton antiporters. - Plant Signal Behav. 4: 265-276, 2009.

Shabala, L., Cuin, T.A., Newman, I.A., Shabala, S.: Salinityinduced ion flux patterns from the excised roots of Arabidopsis sos mutants. - Planta 222: 1041-1050, 2005.

Shi, H., Lee, B.H., Wu, S.J., Zhu, J.K.: Overexpression of a plasma membrane $\mathrm{Na}^{+} / \mathrm{H}^{+}$antiporter gene improves salt tolerance in Arabidopsis thaliana. - Nature Biotechnol. 21: 81-85, 2003.

Shi, H., Quintero, F.J., Pardo, J.M., Zhu, J.K.: The putative plasma membrane $\mathrm{Na}^{+} / \mathrm{H}^{+}$antiporter $\mathrm{SOS} 1$ controls longdistance $\mathrm{Na}^{+}$transport in plants. - Plant Cell 14: 465-477, 2002.

Sottosanto, J.B., Gelli, A., Blumwald, E.: DNA array analyses of Arabidopsis thaliana lacking a vacuolar $\mathrm{Na}^{+} / \mathrm{H}^{+}$ antiporter: impact of $A t N H X 1$ on gene expression. - Plant J. 40: 752-771, 2004.

Tester, M., Davenport, R.: $\mathrm{Na}^{+}$tolerance and $\mathrm{Na}^{+}$transport in higher plants. - Ann. Bot. 91: 503-527, 2003.

Venema, K., Belver, A., Marín-Manzano, M.C., RodríguezRosales, M.P., Donaire, J.P.: A novel intracellular $\mathrm{K}^{+} / \mathrm{H}^{+}$ antiporter related to $\mathrm{Na}^{+} / \mathrm{H}^{+}$antiporters is important for $\mathrm{K}^{+}$ ion homeostasis in plants. - J. biol. Chem. 278: 2245322459, 2003.

Walker, D.J., Leigh, R.A., Miller, A.J.: Potassium homeostasis in vacuolated plant cells. - Proc. nat. Acad. Sci. USA 93: 10510-10514, 1996.

Wang, L., Wu, X., Liu, Y., Qiu, Q.S.: AtNHX5 and AtNHX6 control cellular $\mathrm{K}^{+}$and $\mathrm{pH}$ homeostasis in Arabidopsis: three conserved acidic residues are essential for $\mathrm{K}^{+}$ transport. - PloS ONE 10: e0144716, 2015.

Yang, Q., Chen, Z.Z., Zhou, X.F., Yin, H.B., Li, X., Xin, X.F., Hong, X.H., Zhu, J.K., Gong, Z.: Overexpression of SOS (Salt Overly Sensitive) genes increases salt tolerance in transgenic Arabidopsis. - Mol. Plant 2: 22-31, 2009.

Yoshida, K., Kawachi, M., Mori, M., Maeshima, M., Kondo, M., Nishimura, M., Kondo, T.: The involvement of tonoplast proton pumps and $\mathrm{Na}^{+}\left(\mathrm{K}^{+}\right) / \mathrm{H}^{+}$exchangers in the change of petal color during flower opening of morning glory, Ipomoea tricolor cv. Heavenly Blue. - Plant Cell Physiol. 46: 407-415, 2005.

Yokoi, S., Quintero, F.J., Cubero, B., Ruiz, M.T., Bressan, R.A., Hasegawa, P.M., Pardo, J.M.: Differential expression and function of Arabidopsis thaliana $\mathrm{NHX} \mathrm{Na}^{+} / \mathrm{H}^{+}$ antiporters in the salt stress response. - Plant J. 30: 529-539, 2002.

Yu, C.T., Sze, W.L., Stefan, H., Paul, D., Jiang, L.: Dynamic response of prevacuolar compartments to Brefeldin A in plant cells. - Plant Physiol. 142: 1442-1459, 2006.

Yue, Y., Zhang, M., Zhang, J., Duan, L., Li, Z.: SOS1 gene overexpression increased salt tolerance in transgenic tobacco by maintaining a higher $\mathrm{K}^{(+)} / \mathrm{Na}^{(+)}$ratio. - J. Plant Physiol. 169: 255-261, 2012.

Zahran, H.H., Marín-Manzano, M.C., Sánchez-Raya, A.J., Bedmar, E.J., Venema, K., Rodríguez-Rosales, M.P.: Effect of salt stress on the expression of NHX-type ion transporters in Medicago intertexta and Melilotus inducus plants. Physiol. Plant 131: 122-130, 2007.

Zhang, H., Liu, Y., Xu, Y., Chapman, S., Love, A. J., Xia, T.: A 
newly isolated $\mathrm{Na}^{+} / \mathrm{H}^{+}$antiporter gene, DmNHX1, confers salt tolerance when expressed transiently in Nicotiana benthamiana or stably in Arabidopsis thaliana. -Plant Cell Tissue Organ Cult. 110: 189-200, 2012.

Zhang, W.D., Wang, P., Bao, Z., Ma, Q., Duan, L.J., Bao, A.K.,
Zhang, J.L., Wang, S.M.: SOS1, HKT1;5, and NHX1 synergistically modulate $\mathrm{Na}^{+}$homeostasis in the halophytic grass Puccinellia tenuiflora. - Front Plant Sci. 8: 576-583, 2017. 